\title{
Advances in the Modeling and Control of Micro Hydro Power Stations with Induction Generators
}

\author{
Lucas Giuliani Scherer, Robinson Figueiredo de Camargo, Humberto Pinheiro and Cassiano Rech \\ Federal University of Santa Maria - UFSM \\ CEP: 97105-900 - Santa Maria, RS - Brazil \\ lgscherer@gmail.com,robinson.camargo@gmail.com
}

\begin{abstract}
The interest in technologies related to microgeneration has increased over the last decade. Hydro, wind and solar power represent some of the technologies which had significant improvement. Among these technologies, micro hydro power stations with self-excited induction generators (IG) became an excellent choice for limited power generation in isolated areas, due basically to its robustness and low cost, compared to synchronous machine. This paper describes the controllers for micro hydro power stations for island operation based on nonlinear model of hydraulic turbine with a selfexcited induction generators. Frequency control is obtained by a speed governor applied to the turbine feed system while constant voltage control is reached through reactive power control using a voltage source inverter (VSI). In order to reach effective frequency control, it is proposed the use of a motor flux estimation algorithm to obtain the measurement of instantaneous rotor speed without using a mechanical sensor applied on his shaft resulting in inherent cost reduction. Simulation results are given and they illustrate the transient behavior due step changes in load and frequency reference setting point.
\end{abstract}

\section{INTRODUCTION}

Over the last few years the interest in distributed generation and renewable energy systems, such as hydro, wind, biomass and solar power units has increased considerably. Numerous reasons for such rising interest in sustainable energy sources can be appointed. Among them, it is possible highlight the rising demand for electricity at the same time the world discusses the harmful effect of the use of fossil fuels to the environment and the dangerous of possible nuclear energy disasters. With the present concern about environmental preservation, distributed generation represents the alternative solution for increasing energy demand once it usually has minimum environmental impact and high efficiency.

Among distinct distributed generation alternatives, small hydro power stations using synchronous generators (SG) can be considered the most consolidated ones. The features of the SG associated to the high performance of the technologies applied on its control made possible its application at micro hydro power stations $(<100 \mathrm{~kW})$. However, even with the technical advantages of SG in terms of voltage control, at low power generation stations it still represents a high cost compared to the entire system cost, making its application, sometimes, economically unviable.

A solution for such problem is its substitution by induction generator (IG). With the necessary changes in control system, the IG can represent a good alternative to SG due its lower cost and higher reliability. Comparative studies show significant economic advantages for generation system using induction generators in comparison to SG for micro power generation systems $(<100 \mathrm{~kW})[1]$.

In comparison to other natural competitor in the micro generation area, the permanent magnetic generator (PMG), the induction generator present advantages like lower cost, higher power quality and inherit self-protection, being the only disadvantage its smaller power density $(\mathrm{W} / \mathrm{kg})$, which is not considered relevant for hidro electric generation.

Induction generators represent, as well, an excellent choice for micro generation in isolated areas, due to its well known features of robustness, high power density, reduced maintenance, simple design, self-protection capacity and no necessity of auxiliary DC excitation sources [2].

Several research works have discussed the isolated operation of induction generator and its voltage and frequency regulation. Nevertheless, the matter is commonly not treated in a complete way. For instance, the modeling of the prime mover and water dynamic usually is not considered [3], [4], [5]. Others consider an Electronic Load Control (ELC) for consumption of excessive energy [6] or even the connection of a VSI dc-link to a single-phase utility grid [2] to control the active power consuption and, this way, to maintain constant frequency. Furthermore, to obtain the speed information required by the speed governor control, many authors use speed transducers, such as digital shaft position encoders. The use of such mechanical devices reduces the system reliability of system, especially in adverse environments, and increases the cost of the whole system. 


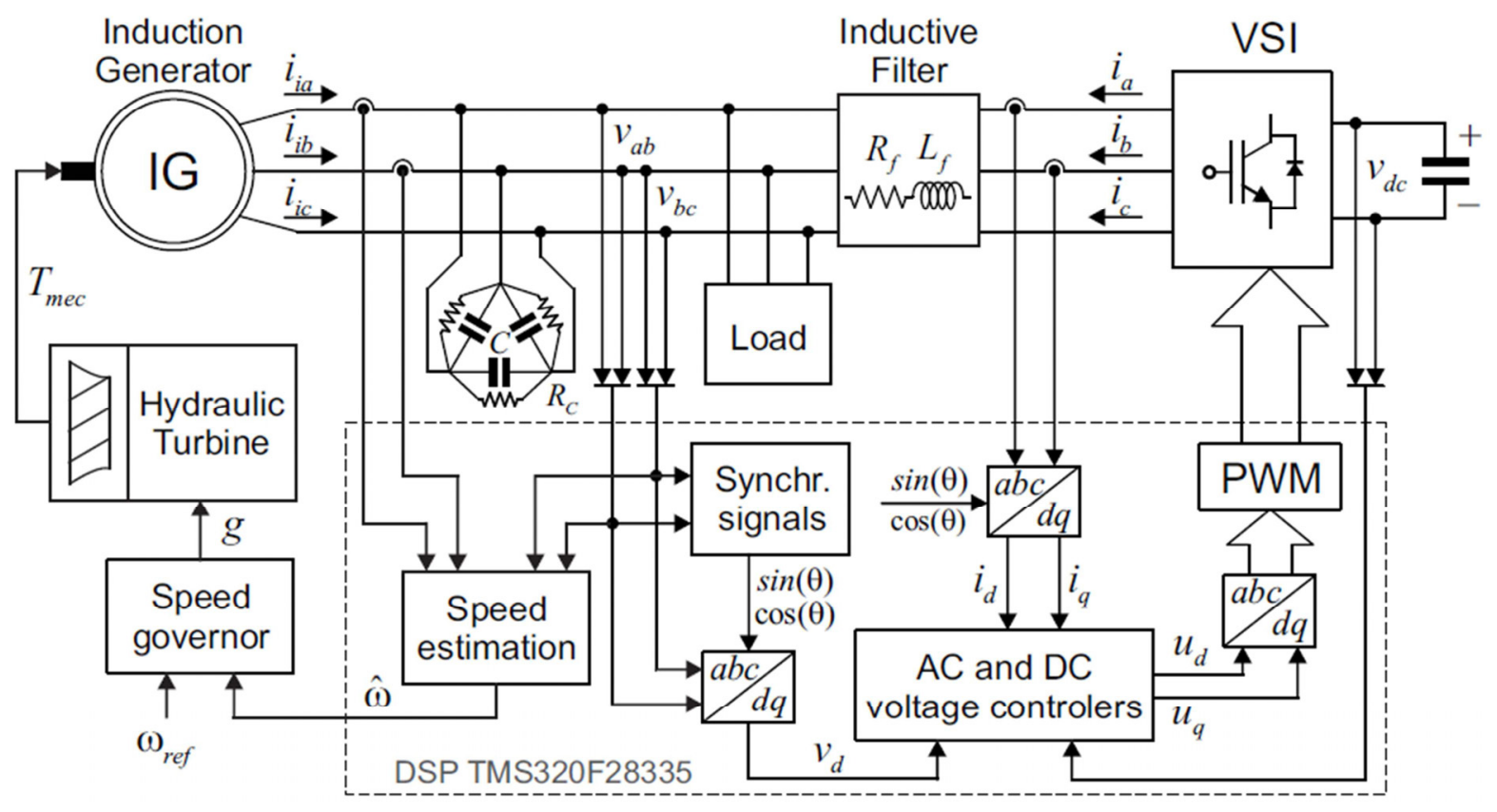

Fig. 1. Proposed system.

As alternatives for such works, this paper proposes some advances with the use of nonlinear model and control of the hydro turbine and speed governor applied on induction generators for island operation. The control of the stator voltages is achieved by the controling the reactive power required by IG and loads. It is accomplished by a voltagesource inverter (VSI) connected in parallel to the voltage bus, which is capable of providing variable reactive power. The parallel connection of VSI instead of a full scale power converter configuration, requires a lower power rated converter, and consequently lower cost, once in parallel connection the VSI only converts just a fraction of system rated power.

The control of stator voltage frequency is obtained by the maintenance of active power balance, i.e. keep the power generated by the hydraulic turbine system matching to the power required by the loads. In this case, it is necessary to have the relationship between generator speed, stator frequency, and real power output, in order to achieve effective frequency control [4].

Another important contribution of the present study is the elimination of the mechanical speed sensor, since the speed is estimated from voltages and currents measurement. This feature results in an expressive cost reduction, mainly for low power generation systems.

Simulation results considering step load changes and frequency variations are shown. Experimental results related to reactive power control and voltage regulation are also presented.

\section{PROPOSED SYSTEM}

The proposed system is shown in Fig. 1 and represents a micro hydro power station. In this study it is considered a power station model, including an induction generator, excitation capacitor bank, hydro turbine and voltage-source inverter (VSI).

\section{A. Frequency Control}

A nonlinear model assuming inelastic water column is considered for the hydro turbine and waterways [7], [8]. This model was chosen because it is adequate for studies involving large power and frequency variations so that it is appropriate for large-signal time-domain simulations.

Considering a simple hydraulic system with a penstock, unrestricted head and tail race, and with either a very large or no surge tank, and assuming yet a rigid conduit and incompressible fluid, the basic hydrodynamic equation are:

$$
\begin{gathered}
U=K_{u} G \sqrt{H} \\
P=K_{P} H U \\
\frac{d U}{d t}=-\frac{a_{g}}{L}\left(H-H_{0}\right) \\
Q=A U
\end{gathered}
$$


where:

$U$ - Water speed.

$G$ - Ideal gate opening.

$H$ - Hydraulic head at gate.

$H_{0}$ - Initial steady-state value of $H$.

$P$ - Turbine power.

$Q$ - Water flow rate.

$A$ - Pipe area.

$L$ - Length of conduit.

$a_{g}$ - Acceleration due to gravity.

$K_{u}, K_{p}$ - Constants of proportionality.

Normalizing (1)-(4) based on rated values, the following expressions that completely describe the water column and turbine features are obtained:

$$
\begin{gathered}
\bar{H}=\left(\frac{\bar{U}}{\bar{G}}\right)^{2} \\
\overline{\bar{U}}=\frac{-1}{T_{W} s} \\
T_{W}=\frac{L U}{a_{g} H_{r}}=\frac{L Q_{r}}{a_{g} A H_{r}} \\
\bar{T}_{m}=\left(\frac{\omega_{0}}{\omega}\right) \bar{P}_{m}\left(\frac{P_{r}}{M V A_{\text {base }}}\right)=\frac{1}{\bar{\omega}}\left(\bar{U}-\bar{U}_{N L}\right) \bar{H} \bar{P}_{r} \\
\bar{G}=A_{t} \bar{g} \\
A_{t}=\frac{1}{\bar{g}_{F L}-\bar{g}_{N L}}
\end{gathered}
$$

where the subscript " $r$ " denotes rated value, and over-bar "

" denotes per unit value:

$T_{W}$ - Water starting time at rated load.

$\bar{T}_{m}$ - Per unit turbine mechanical torque.

$\overline{P_{r}}$ - Per unit turbine rating $=\frac{\text { turbine } \mathrm{MW} \text { rating }}{M V A_{\text {base }}}$

$\bar{U}_{N L}-$ Water speed at no load.

$\bar{\omega}$ - Per unit speed.

$\bar{g}_{N L}$ - Gate opening at no load.

$\bar{g}_{F L}$ - Gate opening at rated load.
Fig. 2 shows a block diagram which represents the nonlinear model of the hydraulic turbine.

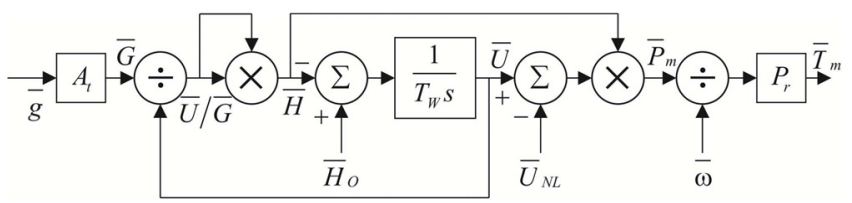

Fig. 2. Nonlinear model of hydraulic turbine.

Due to the water inertia, the hydraulic turbine is considered a "non-minimal phase" system. Taking into consideration this peculiar effect, the frequency compensator transfer function must include a time constant to delay its output signal, and consequently the action of the actuator till the inverse response has extinguished [9].

Considering such characteristic, it is therefore applied a proportional-derivative (PD) controller with a derivative time constant, represented by the following equation:

$$
G_{C_{-} S G(s)}=k_{P}+\frac{k_{D} s}{1+N s}
$$

where:

$k_{P}$ - Proportional gain.

$k_{D}$ - Derivative gain.

$N$ - Time constant for derivative action.

Fig. 3 present the block diagram of the hydraulic turbine actuators and frequency control considered.

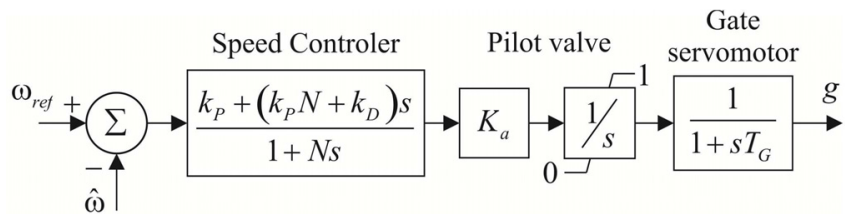

Fig. 3. Speed governor diagram blocks.

The effectiveness of the frequency control depends on the measurement of the rotor speed. However, to reduce the cost of the control system, a rotor speed estimation algorithm is used.

\section{B. Speed Estimation}

Speed estimation of induction motors depends on effective estimation of stator and rotor fluxes. For small frequency deviations, satisfactory results are obtained by using the stator voltage model, which estimates the flux from the stator voltage and current [10]-[12], as can be observed in Fig. 4. 


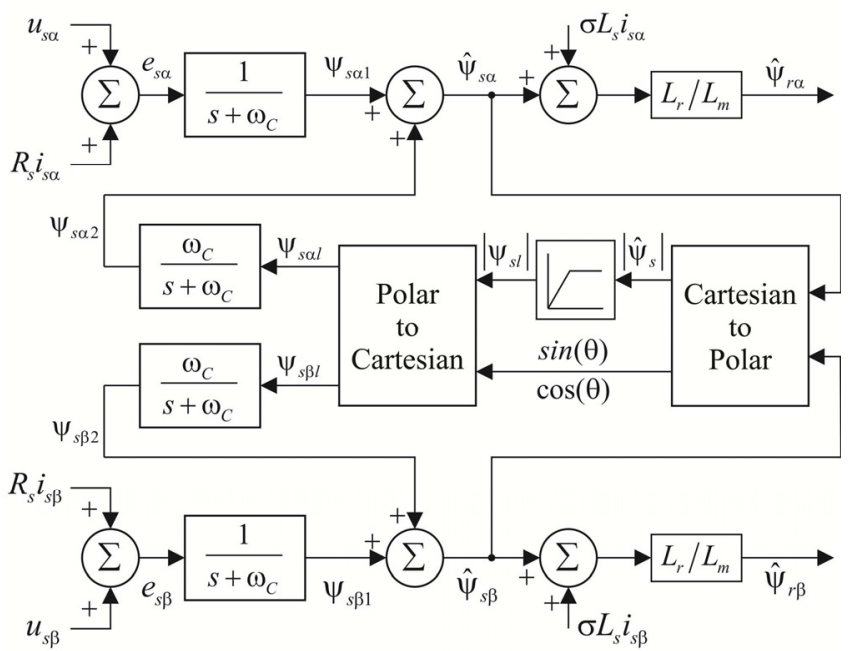

Fig. 4. Block diagram of the stator and rotor flux estimator.

Rotor speed is then indirectly obtained from:

$$
\begin{gathered}
\hat{\omega}=\hat{\omega}_{s}-\hat{\omega}_{s l} \\
\hat{\omega}_{s}=\frac{\hat{\psi}_{s \alpha}\left(u_{s \beta}-R_{s} i_{s \beta}\right)-\hat{\psi}_{s \beta}\left(u_{s \alpha}-R_{s} i_{s \alpha}\right)}{\hat{\psi}_{s \alpha}{ }^{2}+\hat{\psi}_{s \beta}{ }^{2}} \\
\hat{\omega}_{s l}=\frac{L_{m} i_{s q}}{\tau_{r} \hat{\psi}_{r d}}
\end{gathered}
$$

where:

$\hat{\omega}$ - Rotor speed.

$\hat{\omega}_{s}$ - Synchronous frequency.

$\hat{\omega}_{s l}$ - Rotor slip frequency.

$R_{s}$ - Stator resistance.

$L_{r}$ - Rotor inductance.

$L_{s}$ - Stator inductance.

$L_{m}$ - Magnetizing inductance.

$\hat{\psi}_{r d}$ - Estimated rotor flux in $d$ axis.

$\tau_{r}=\frac{L_{r}}{R_{r}}-$ Rotor time constant.

$\sigma=1-\frac{L_{m}^{2}}{L_{s} L_{r}}-$ Leakage coefficient.

\section{Voltage Control}

As shown in Fig. 1, the proposed system is composed of a VSI with an output filter $L_{f}$ and a delta connected excitation capacitors bank. To simplify the model, IG and dc-link capacitor are assumed to be ideal voltage sources. Based on this assumption, the following state space representation in $d q$ axes is obtained:

$$
\begin{aligned}
& {\left[\begin{array}{c}
\dot{i}_{d} \\
\dot{i}_{q} \\
\dot{v}_{d} \\
\dot{v}_{q}
\end{array}\right]=\left[\begin{array}{cccc}
-\frac{R_{f}}{L_{f}} & -\omega_{s} & \frac{Z_{\text {base }}}{L_{f}} & 0 \\
\omega_{s} & -\frac{R_{f}}{L_{f}} & 0 & \frac{Z_{\text {base }}}{L_{f}} \\
\frac{1}{Z_{\text {base }} C} & 0 & -\frac{1}{C R_{C}} & -\omega_{s} \\
0 & \frac{1}{Z_{\text {base }} C} & \omega_{s} & -\frac{1}{C R_{C}}
\end{array}\right]\left[\begin{array}{c}
i_{d} \\
i_{q} \\
v_{d} \\
v_{q}
\end{array}\right]+} \\
& +\left[\begin{array}{cc}
-\frac{Z_{\text {base }}}{L_{f}} & 0 \\
0 & -\frac{Z_{\text {base }}}{L_{f}} \\
0 & 0 \\
0 & 0
\end{array}\right]\left[\begin{array}{cc}
0 & 0 \\
0 & 0 \\
u_{d_{-} p w m} \\
u_{q_{-} p w m}
\end{array}\right]+\left[\begin{array}{cc}
\frac{1}{Z_{\text {base }} C} & 0 \\
0 & \frac{1}{Z_{\text {base }} C}
\end{array}\right]\left[\begin{array}{l}
i_{i d} \\
i_{i q}
\end{array}\right]
\end{aligned}
$$

where:

$R_{C}$ - Damping resistor.

$Z_{\text {base }}=v_{\text {base }} / i_{\text {base }}$ - Base impedance.

$i_{d}, i_{q}$ - VSI currents in $d q$ axes.

$v_{d}, v_{q}$ - Bus voltages in $d q$ axes.

$u_{d_{-} p w m}, u_{q_{-} p w m}$ - VSI voltages in $d q$ axes.

$i_{i d}, i_{i q}$ - IG currents in $d q$ axes.

According to Fig. 1, the digital control system proposed here requires only seven sensors: one for the measurement of the VSI dc-link voltage, two for IG ac voltages, two for IG ac currents and two for VSI compensation currents.

Two control loops are employed to control the PWMVSI, as shown in Fig. 5. Both loops, internal and external, use proportional-integral (PI) controllers. The dc-link voltage is kept constant at a reference value by the control of $d$ axis VSI current. Similarly, the control of ac voltages amplitudes generated by the IG is accomplished by controlling the reactive power flow, represented by q axis VSI current [13].

The comparison of dc bus voltage $\left(v_{d c}\right)$ to a reference value $\left(v_{d c}{ }^{*}\right)$ is the input of a PI controller, which generates the $d$-axis reference current $\left(i_{d}{ }^{*}\right)$. 


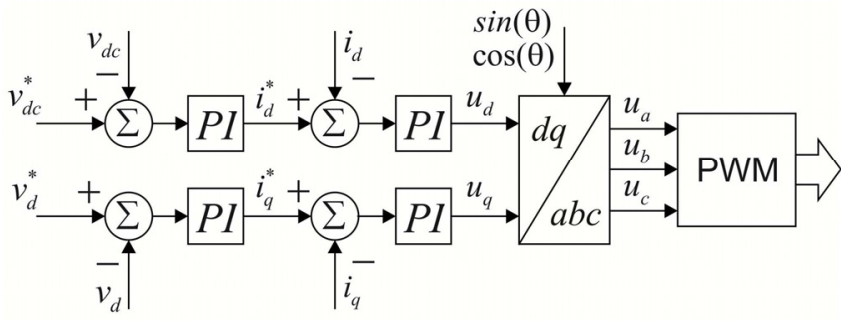

Fig. 5. Block diagram of the PWM-VSI control system.

The $d$-axis inverter current $\left(i_{d}\right)$ controls the active power flow through the PWM inverter. Similarly, the error between the IG output voltage in the $d$-axis $\left(v_{d}\right)$ and its reference value $\left(v_{d}{ }^{*}\right)$ is the input of another PI controller, generating the $q$-axis reference current $\left(i_{q}^{*}\right)$. The $q$-axis inverter current $\left(i_{q}\right)$ controls the reactive power flow through the PWM-VSI. The errors between the reference currents obtained from the outer loop voltage controllers and the measured currents are the inputs of PI current controllers, which generate the control signals in the $d q$-axis $\left(u_{d}\right.$ and $\left.u_{q}\right)$.

The parameters of PI controllers are defined based on the transfer functions derived from (15) in the discrete time and are showed below:

$$
\begin{gathered}
G_{V_{d}(\mathrm{Z})}=\frac{v_{d}}{i_{q}}=\frac{-2.815 \times 10^{-8}-1.126 \times 10^{-7} Z^{-1}-2.815 \times 10^{-8} Z^{-2}}{1-1.999 Z^{-1}+1 Z^{-2}} \\
G_{V_{C C}(Z)}=\frac{V_{C C}}{i_{d}}=\frac{-0.02136-0.02136 Z^{-1}}{1-1 Z^{-1}} \\
G_{i_{d-i}(Z)}=\frac{i_{d}}{u_{d}}=\frac{i_{q}}{u_{q}}=\frac{-0.664-0.0007833 Z^{-1}+0.6624 Z^{-2}}{1-1.995 Z^{-1}+0.9965 Z^{-2}}
\end{gathered}
$$

\section{SIMULATION RESULTS}

The generation system shown in Fig. 1 has been simulated with SimPower Systems toolbox of the Matlab/Simulink ${ }^{\circledR}$. Table I presents parameters of the induction generator and capacitor bank, and Table II shows parameters of the voltage-source inverter, output filter and voltage controllers, considered for simulation. Table III presents parameters considered for hydraulic turbine and speed governor system.

Fig. 6 presents the response to a step change in frequency (speed) reference, from 377 to $450 \mathrm{rad} / \mathrm{s}$ at $25 \mathrm{~s}$. The disturbance noticed at $5 \mathrm{~s}$ is due the opening of the gate of hydraulic system. The closed-loop system has a satisfactory performance, considering the slow dynamic of a hydraulic system. Fig. 7 shows the response of the speed estimation algorithm under a $30 \%$ step load change at 20 s, which results in a steady-state estimation error smaller than $1 \%$ after the step load change.

TABLE I. GENERATOR AND CAPACITOR BANK PARAMETERS

\begin{tabular}{|c|c|}
\hline Parameter & Value \\
\hline Generator power & $5 \mathrm{HP}$ \\
\hline Rated voltage & $220 \mathrm{~V}(\Delta$ connection $)$ \\
\hline Rated speed & $1730 \mathrm{rpm}$ \\
\hline Rated frequency & $60 \mathrm{~Hz}$ \\
\hline Stator resistance & $0.66 \Omega$ \\
\hline Rotor resistance & $0.264 \Omega$ \\
\hline Stator leakage reactance & $0.935 \Omega$ \\
\hline Rotor leakage reactance & $0.935 \Omega$ \\
\hline Rotor inertia & $0.034 \mathrm{~kg} \cdot \mathrm{m}^{2}$ \\
\hline Capacitor bank & $40 \mu \mathrm{F}($ each $)$ \\
\hline
\end{tabular}

TABLE II. INVERTER AND VOLTAGE CONTROLLERS PARAMETERS

\begin{tabular}{|c|c|}
\hline Parameter & Value \\
\hline Maximum current $r m s$ & $20 \mathrm{~A}$ \\
\hline Maximum dc-link voltage & $450 \mathrm{~V}$ \\
\hline Output filter $\left(L_{f}, R_{f}\right)$ & $(1.7 \mathrm{mH}, 0.03 \Omega)$ \\
\hline Inner control loop crossover frequency & $600 \mathrm{~Hz}$ \\
\hline$V_{C C}$ control loop crossover frequency & $377 \mathrm{~Hz}$ \\
\hline$v_{d}$ control loop crossover frequency & $0.0005 \mathrm{~Hz}$ \\
\hline Switching frequency & $10 \mathrm{kHz}$ \\
\hline Inner control loop PI gains $\left(k_{p i}, k_{i i}\right)$ & $(-0.2888,-105)$ \\
\hline$V_{C C}$ control loop PI gains $\left(k_{p c c}, k_{i c c}\right)$ & $(-5.406,-4004)$ \\
\hline$v_{d}$ control loop PI gains $\left(k_{p v}, k_{i v}\right)$ & $(-0.3015,-30)$ \\
\hline
\end{tabular}

TABLE III. HYDRAULIC TURBINE AND SPEED CONTROLLER PARAMETERS

\begin{tabular}{|c|c|}
\hline Parameter & Value \\
\hline Water starting time $\left(T_{W}\right)$ & 0.8737 \\
\hline Proportional gain $\left(k_{P}\right)$ & 0.1 \\
\hline Derivative gain $\left(k_{D}\right)$ & 0.35 \\
\hline Time constant for Derivative $(N)$ & $0.01 \mathrm{~s}$ \\
\hline Servo gain $\left(K_{a}\right)$ & 3.5 \\
\hline Main servo time constant $\left(T_{G}\right)$ & $0.1 \mathrm{~s}$ \\
\hline
\end{tabular}

By the same way, Fig. 7 shows a load step of $30 \%$ being applied in time 20s and the good performance of speed estimation algorithm, witch presented less than $1 \%$ error in steady state after the application of load step. 


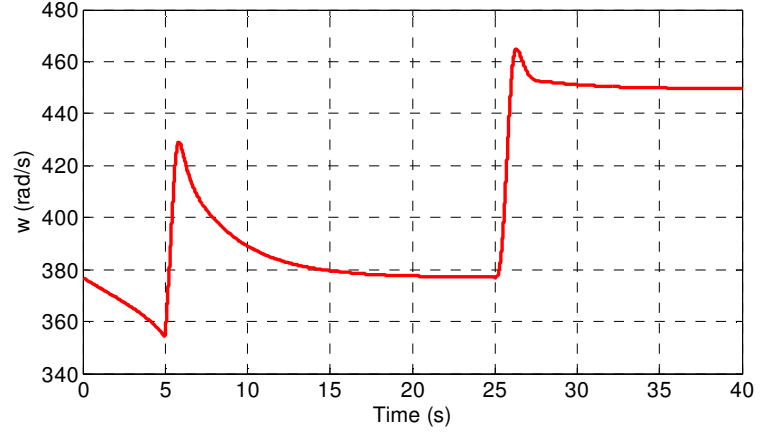

Fig. 6. Response to step change in frequency reference.

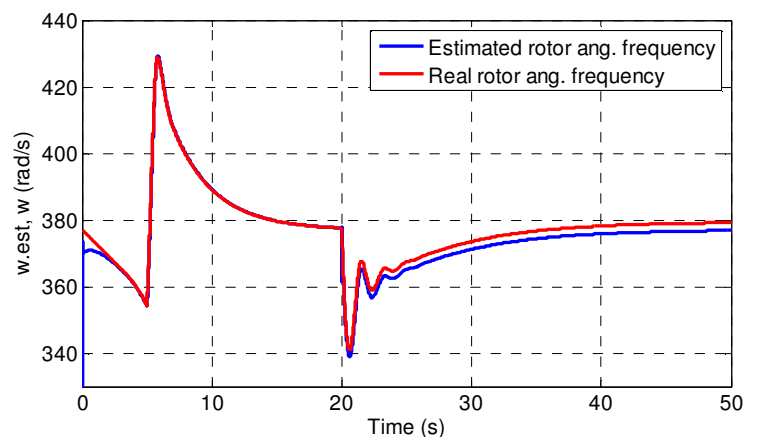

Fig. 7. Response of the speed estimation during a 30\% load step change.

The response of voltage controller inner loops can be simulated short-circuiting the inductive filter output and fixing values for $d q$-axis reference current $\left(i_{d}{ }^{*}\right.$ and $\left.i_{q}{ }^{*}\right)$. The expected response is presented in Fig. 8, with the $d q$-axis currents generated by VSI following the reference currents imposed.

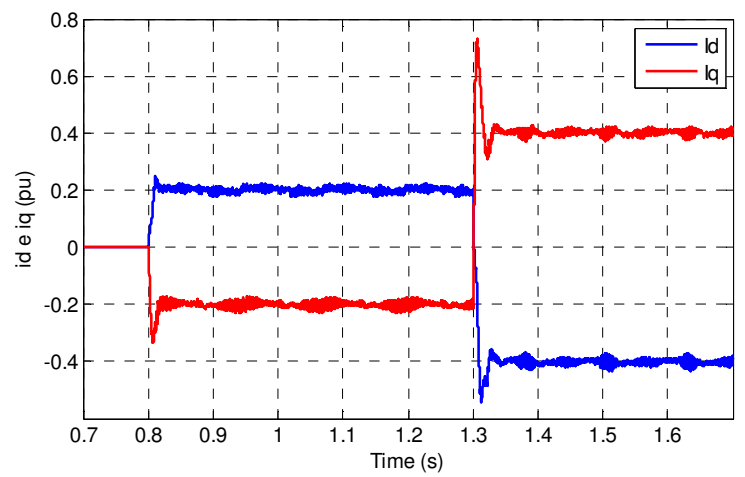

Fig. 8. Response of VSI currents under reference currents changes.

In Fig. 8 the control starts operating at $0.8 \mathrm{~s}$ with $i_{d}{ }^{*}$ and $i_{q}^{*}$ values equal to $0.2 \mathrm{pu}$ and $-0.2 \mathrm{pu}$, respectively. In time
$1.3 \mathrm{~s}, i_{d}{ }^{*}$ and $i_{q}{ }^{*}$ reference currents value change for $-0.4 \mathrm{pu}$ and 0.4 pu respectively.

Fig. 9 shows the response of the dc-link voltage control from beginning of control actuation till it reaches the steadystate value. Fig. 10 shows ac voltage control by increasing the load $(+30 \%)$ at $40 \mathrm{~s}$ and by decreasing the load $(-30 \%)$ at $40,5 \mathrm{~s}$.

By similar way, the performance of frequency control is presented in Fig. 11, under 15\% load input at 35s, and output at $45 \mathrm{~s}$. The frequency control is designed to a specific load condition. For different load conditions the frequency control gains must be re-designed.

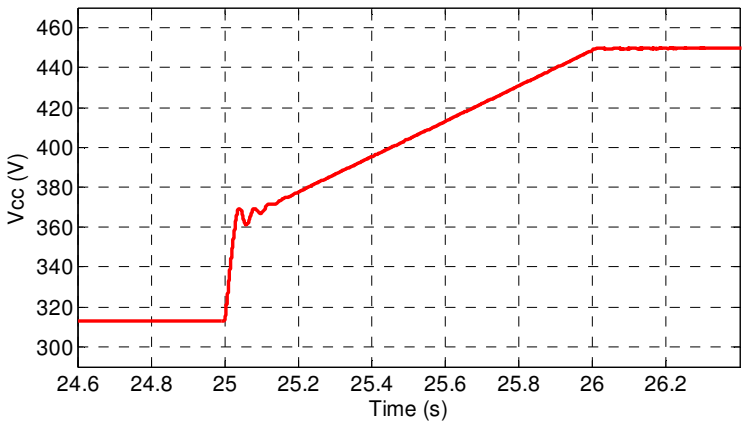

Fig. 9. DC-link voltage control.

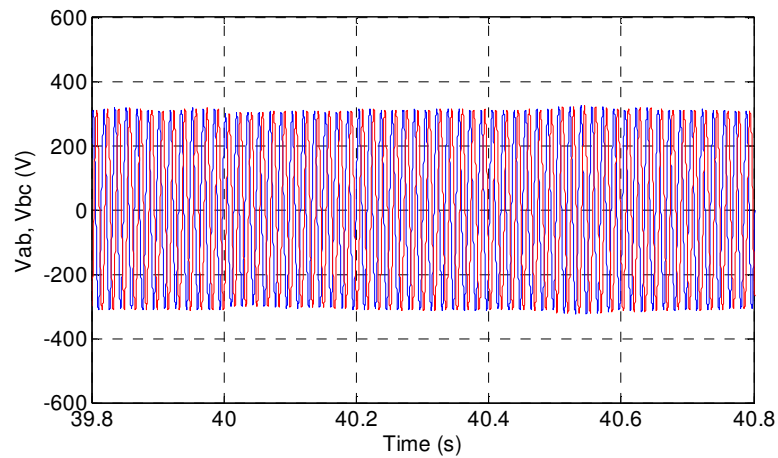

Fig, 10. AC-voltage regulation under load step.

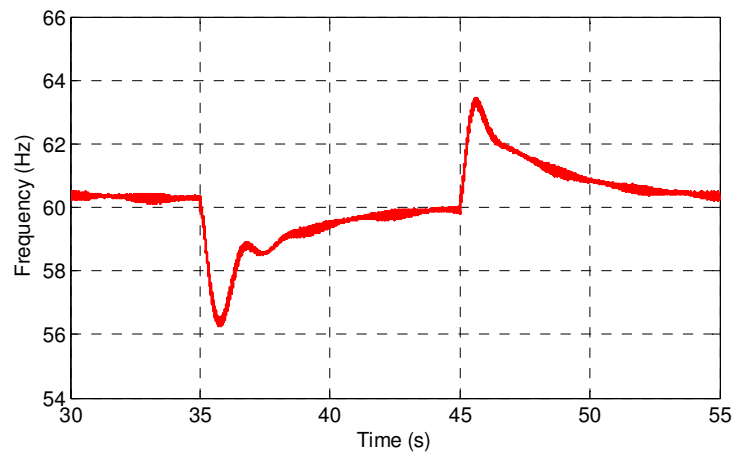

Fig, 11. Frequency regulation under load step. 


\section{EXPERIMENTAL RESULTS}

A prototype considering a $5 \mathrm{HP}(3.73 \mathrm{~kW})$ induction generator was built in our lab to carry out the experimental tests based in the generation system presented in Fig. 1. To emulate the behavior of the turbine and waterways a $7.5 \mathrm{HP}$ three-phase induction motor is directly coupled to the generator shaft through a flexible coupling and driven by a dedicated adjustable-speed drive. The digital control system was implemented with a floating point DSP TMS320F28335 from Texas Instruments.

The excitation of IG is shown in Fig. 12. The bank of capacitor connected in delta supplies the reactive power required by generator during the start-up. The steady-state value of ac voltage is determined by the capacitance applied.

Fig. 13 shows the experimental response of dc-link voltage control. It is imposed a soft starting in order to avoid large peaks of voltage, what could cause capacitor deterioration.

In Fig. 14 it is presented the experimental response of ac voltage control under $30 \%$ load input and output, respectively.

Notice the similarity between experimental response and simulation response showed in Fig. 9 and 10 respectively.

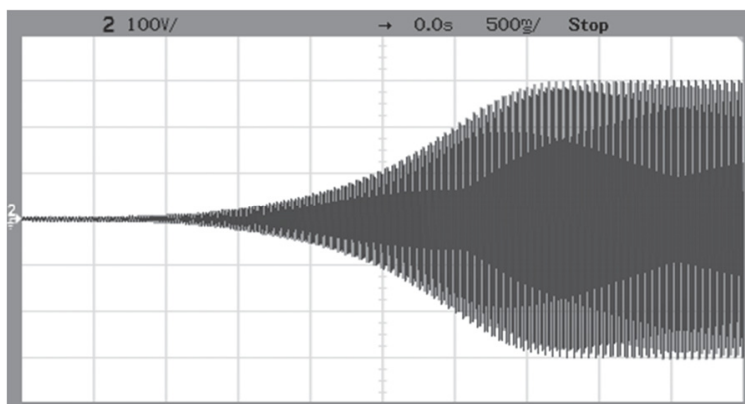

Fig. 12. Induction generator excitation.

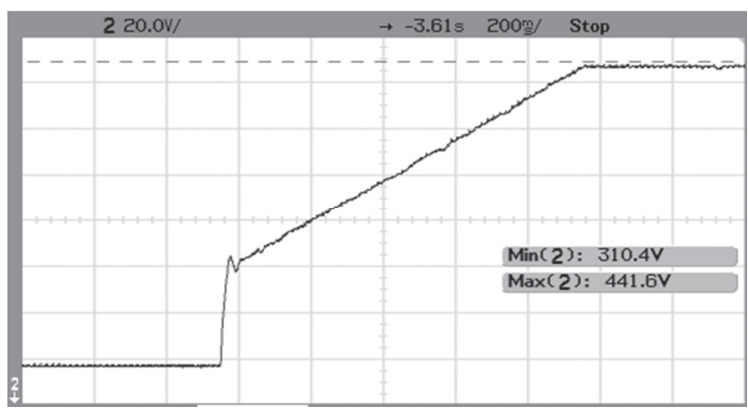

Fig. 13. DC-link voltage control.

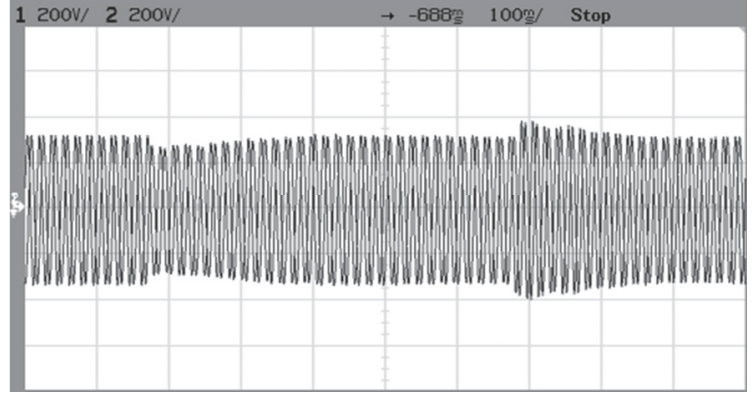

Fig. 14. AC-voltage regulation under load step.

\section{CONCLUSION}

This paper proposed some advances in the modeling and control of micro hydro power stations based on nonlinear modeling of hydraulic turbine, considering real application parameters and limitations. Nonlinear model, in comparison to the linear model, is more appropriate for large-signal timedomain simulations, which is desirable for studies involving large variations in power output and frequency.

Full modeling of system, including electric and hydraulic parameters of plant, even that considering some simplifications, showed excellent response when comparing simulation and experimental results.

Simulations results were essential in the validation of the modeling method. Although the designs of controllers have been based in system transfer functions, simulations showed extreme importance in the adequacy of the PI and PD controllers. At the end, results obtained applying proposed voltage and frequency control presented good performance in island operation, showing that the proposed system can operate within a wider speed range, confirming the efficiency of the proposed control system and estimation algorithm.

A laboratory prototype for the IG system has been implemented to validate the proposed method. Experimental results proved high voltage regulation performance even that employing simple PI controllers.

Looking for a low cost solution in micro power generation for application in isolated areas, the self-excited induction generator associated to a suitable control system presented an adequate performance, even that driven by a hydraulic turbine, whose slow dynamic response imposes challenges in control study. The inherently poor voltage regulation can be overcome with the adoption of digital control techniques in association to reactive power sources. By the same way, the maintenance of voltage frequency requires greater efforts in gate opening control, demanding more agility of mechanical system or even the adoption of instantaneous active power sources connected to the system. 


\section{ACKNOWLEDGMENT}

The authors thank CNPq and FAPERGS for financial support and in special way to Voges Motors for the donation of two induction machines which made possible the development of this research work.

\section{REFERENCES}

[1] J. -M. Chapallaz, J. Dos Ghali, P. Eichenberger and G. Fischer, "Manual on Induction Motors Used as Generators," Vieweg, Braunschweig, 1992.

[2] R. Q. Machado, S. Buso and J. A. Pomilio, "Electronically controlled bi-directional connection of induction generator with a single-phase grid," in IEEE Industrial Electronics Society Conference IECON 2001, v. 3, p. 1982-1987, 2001.

[3] Y.K. Chauhan, S.K. Jain and B. Singh, "A Prospective on Voltage Regulation of Self-Excited Induction Generators for Industry Applications," in IEEE Transactions on Industry Applications, vol. 46, no. 2, pp. 720-730, March/April 2010.

[4] W.L. Chen, and Y.Y. Hsu, "Experimental Evaluation of an Isolated Induction Generator with Voltage and Frequency Control," in IEEE 2006 International Symposium on Power Electronics, Electrical Drives, Automation and Motion, 2006, pp. 497-502.

[5] E. G. Marra, and J. A. Pomilio, "Induction-Generator-Based System Providing Regulated Voltage with Constant Frequency," IEEE Transaction on Industrial Electronics, vol. 47, no. 4, pp. 908-914, Aug. 2000.

[6] B. Singh, S. S. Murthy, and S. Gupta, "Analysis and Design of Electronic Load Controller for Self-Excited Induction Generators," IEEE Transactions on Energy Conversion, vol. 21, no. 1, pp. 285-293, Mar. 2006.

[7] Working Group on Prime Mover and Energy Supply Models for System Dynamic Performance Studies, "Hydraulic Turbine and Turbine Control Models for System Dynamic Studies," IEEE Transactions on Power Systems, vol. 7, no. 1, pp. 167-179, Febr. 1992.

[8] P. Kundur, Power System Stability and Control, McGrawHill, New York, 1994.

[9] J. Björnstedt, and O. Samuelsson, "Voltage and Frequency Control for Island Operated Induction Generators," in CIRED Seminar 2008: SmartGrids for Distribution, 2008, pp.1-4.

[10] J. Hu and b. Wu, "New Integration Algorithms for Estimating Motor Flux over a Wide Speed Range," IEEE Transactions on Power Electronics, vol. 13, no. 5, pp. 969-977, Sept. 1998.

[11] G. Wang, D. Xu, Y. Yu, and W. Chen, "Improved Rotor Flux Estimation Based on Voltage Model for Sensorless Field-Oriented Controlled Induction Motor Drives," in IEEE 2008 Power Electronics Specilists Conference, 2008, pp. 1887-1890.

[12] K. Zhao, and X. You, "Speed Estimation of Induction Motor Using Modified Voltage Model Flux Estimation," in IEEE 2009 International Power Electronics and Motion Control Conference, 2009, pp. 1979-1982.

[13] C. Rech, R. F. de Camargo, M. de Campos, F. Salvadori, G. V. Leandro and J. C. O. Bolacell, "Performance Analysis of Synchronization Methods for Self-Excited Induction Generators," IEEE Power Electronics Specialists Conference PESC 2008, pp. 3378-3384, 2008. 